\title{
A semiótica no/do teatro em La persistencia, de Giselda Gambaro
}

\author{
Edson Santos Silva \\ (Universidade de São Paulo) \\ Orlando Luiz de Araújo \\ (Universidade de São Paulo) \\ Wilma Rigolon \\ (Universidade do Estado de São Paulo)
}

RESUMO: A partir da análise da peça La persisitencia, de Giselda Gambaro, serão apresentados alguns elementos responsáveis pela semiótica do fazer teatral, no tocante às marcas da enunciação que manifestam o discurso, para que o público, ao apreender o sentido dessa linguagem, construa, interprete, avalie, aprecie ou rejeite essas significações.

PALAVRAS-CHAVE: fazer-teatral; enunciação; semiótica

ABSTRACT: From the analysis of the play La persistencia, by Giselda Gambaro, some elements concerning the semiotics of the making of drama will be presented, in respect to the elements of discourse, so that the audience, in learning the meaning of this language, may construct, interpret, evaluate, accept or reject these meanings.

KEYWORDS: theater-making; speech; semiotics 
$\mathrm{O}$ espaço teatral é o local, por excelência, em que os signos proliferam e dialogam entre si e é por meio de várias linguagens que o público pode identificar as diversas situações de enunciação.

Com o intuito de se comprovar tal assertiva, será analisada a peça La Persistencia, uma comovente tragédia contemporânea, da dramaturga e escritora argentina Giselda Gambaro, levada à cena pela diretora Cristina Banegas, no Teatro San Martín, Buenos Aires, com os atores Carolina Fal, Gabo Correa, Horacio Acosta e Sandro Nunziata. Pretende-se, assim, apresentar uma análise de alguns elementos responsáveis pelo fazer teatral, que, partindo de alegorias, reflete sua contemporaneidade à luz do passado.

A Semiótica estuda o sentido; "a semiótica se interessa pelo "parecer do sentido', que se apreende por meio das formas da linguagem e, mais concretamente, dos discursos que se manifestam, tornando-o comunicável e partilhável, ainda que parcialmente" (Bertrand, 2003:11). Segundo Lúcia Santaella, tem por objeto "o exame dos modos de constituição de todo e qualquer fenômeno de produção de significação e de sentido" (1983:13).

Assim, a aplicação da Semiótica apresenta uma diversidade de domínios de aplicação, como uma metodologia de análise de discursos e de textos em que o parecer do sentido se apreende por meio das formas da linguagem, principalmente alegórica, dos discursos que manifestam, tornando-o comunicável e partilhável; abrange as diferentes linguagens que lhe dão forma de expressão: verbal, não-verbal e sincrética.

Conforme Paul Ricouer, "o sujeito não se conhece a si mesmo diretamente, mas só por meio dos signos depositados em sua memória e em seu imaginário pelas grandes culturas." Portanto, a linguagem teatral é um produto interdisciplinar, ou seja, é "um discurso com vocação científica sobre o sentido e tem ligação com as produções significantes e transculturais das sociedades que o modelam e com os postulados epistemológicos que fundamentam as condições de sua análise" (Bertrand, 2003).

Se o sentido é o objeto da Semiótica, seu domínio é vasto, sendo apreendido por meio das formas da linguagem e, mais concretamente, da manifestação dos discursos. Ao público, cabe apreender o sentido dessa linguagem, construindo, interpretando, avaliando, apreciando, compartilhando ou rejeitando as significações apresentadas, o que garante o exercício da representação.

Nesse enfoque, as teorias semióticas podem ser aplicadas ao discurso teatral; ao se analisar o nível discursivo, observa-se que é composto por enunciados de debreagem enunciativa, ou seja, as projeções da enunciação são com a pessoa do "eu", o espaço do "aqui" e o tempo do "agora". Ao se ler uma tragédia, pode-se identificar a predominância da projeção do atual, do agora, em que os discursos tendem a ser em primeira pessoa. Além dessas características, o discurso teatral apresenta as marcações de ações das personagens, que podem aparecer em terceira pessoa, mas com função de primeira pessoa. E assim, constitui-se a embreagem, (articulação do enunciado à situação de enunciação) a suspensão das oposições de pessoa.

No repertório teatral,

a palavra é proferida num cenário, associa-se a mímicas, a jogos de cena. Mas seu traço mais evidente é sua duplicidade, que a faz participar de duas situações de enunciação ao mesmo tempo: 
a) na primeira, um autor se dirige a um público através da representação de uma peça; é, portanto, a representação que constitui o ato de enunciação;

b) na segunda, a situação representada, personagens trocam frases num contexto enunciativo supostamente autônomo com relação à representação.

(Maingueneau, 1996:159)

As duas situações de enunciação diferem: a relação entre autor e público é dissimétrica, enquanto os personagens podem se alternar na posição de enunciação e de co-enunciação. Dessa maneira, as ações dos atores baseiam-se em princípios semióticos, constituindo-se em uma transformação do estado inicial do sujeito. Em cena, as enunciações apresentam-se como proferidas espontaneamente por personagens ou apenas atualizam enunciados anteriormente escritos. Quanto ao público, fica enleado numa situação de enunciação em que recebe enunciados em palimpsesto: as palavras ditas em cena só surgem defasadas de si mesmas, duplicadas pelo escrito que deixam transparecer. Portanto, essa instabilidade enunciativa remete à possibilidade de leituras polissêmicas da obra teatral.

Pode-se afirmar, então, que a enunciação teatral, em muitos momentos, reflete sua contemporaneidade à luz alegórica do passado, retomando temas e situações. Neste contexto, faz-se mister apresentar alguns conceitos de alegoria, a fim de explicitar com maior clareza o proposto.

S.F. 1. Exposição de um pensamento sob forma figurada. 2. Ficção que representa uma coisa para dar uma idéia de outra. 3. Seqüências de metáforas que significam uma coisa nas palavras e outras no sentido. 4. Obra de pintura ou de escultura que representa uma idéia abstrata por meio de formas que a tornam compreensível. 5. Simbolismo concreto que abrange o conjunto de toda uma narrativa ou quadro, de maneira que a cada elemento do símbolo corresponda um elemento significado ou simbolizado (Aurélio, 1999).

A alegoria consiste num discurso que faz entender outro numa linguagem que oculta outra. Pondo de parte divergências doutrinárias acerca do conceito preciso que o vocábulo encerra, podemos considerar alegoria toda concretização, por meio de imagens, figuras e pessoas, de idéias, qualidades ou entidades abstratas. $\mathrm{O}$ aspecto material funcionaria como disfarce, dissimulação, ou revestimento, do aspecto moral, ideal ou ficcional. Visto que a narração constitui o expediente mais adequado à concretização do mundo abstrato, tem-se como certo que a alegoria implica sistematicamente um enredo, teatral ou novelesco. E daí a impressão de equivaler a uma seqüência logicamente ordenada de metáforas: o acordo entre o plano concreto e o plano abstrato processa-se minúcia a minúcia, elemento a elemento, e não em sua totalidade (Massaud Moisés, 1995).

[...] un récit de caractère symbolique ou allusif. En tant que narration, elle est un enchainement d'actes; elle met en scène des personnages (êtres humains, animaux, abstractions personnifièes) dont les atributs et le costume, dont les faits et gestes ont valeur de signes, et qui se meuvent dans un lieu et dans un temps qui sont eux mêmes des symboles (Morier, 1989) ${ }^{1}$. 
Morier amplia ainda mais sua definição ao afirmar que a alegoria é um sistema de relação entre dois mundos: “[...] l'un qui est l'aspect immédiat et littéral du texte; l'autre qui en est la signification morale, psycologique ou théologique"2.

A novidade na definição desse termo reside no fato de que não pode haver alegoria com uma representação plástica de uma realidade abstrata, é fundamental que o "objeto" seja animado, fale, faça qualquer ação para merecer o título de alegoria, ou seja, "est un masque et une arme politique" (é uma máscara e uma arma política). Sendo simulacro do que se quer dizer e ao mesmo tempo instrumento político, a alegoria traz em seu bojo "intention pédagogique" (intenção pedagógica).

Pode-se deduzir, então, que a alegoria é um discurso sob cuja figuração ao dizer A se esconde um sentido B, significa outra coisa que não é o que está, necessariamente, explícito no texto verbal. Por ser um pensamento que se expande como uma metáfora continuada, a alegoria implica um enredo que pode ser teatral ou novelesco: sob o aspecto ou a aparência de uma história concretizada num tempo e num espaço, subjaz um segundo e outro sentido. Ou ainda, sob a figuração que se concretiza material e presentemente na ação, no tempo, no espaço, nos personagens, oculta-se um sentido que se desvela à medida que se descobrem as equivalências e correlações entre a realidade dita e referida e a que por trás se esconde.

Portanto, quando se afirma que o autor teatral, simbolicamente representado no seu texto, lê sua contemporaneidade à luz alegórica do passado, entende-se que as peças, ambientadas no passado, são um discurso (A), sob cuja figuração se esconde a contemporaneidade (B). Semioticamente, constitui-se a embreagem, a articulação do enunciado à situação de enunciação e a debreagem, o "eu", o "aqui” e o "agora".

Sabe-se que a alegoria foi usada à exaustão pelo teatro romântico e, em especial, pelo Teatro Romântico Português. Garrett, renovador da cena teatral e introdutor do Romantismo em Portugal, utilizará esse expediente retórico em várias obras dramáticas, entre as quais Um auto de Gil Vicente, e em sua obra-prima, Frei Luís de Sousa. Em ambas, percebe-se de forma patente um viés semiótico do gênero dramático, ou seja, pela intersecção de signos o palco torna-se, além de uma arena em que se digladiam os signos, um grande meio de civilização em que autor-público-texto e signos se desorganizam , podendo-se, a partir da dramatização, organizarem-se em uma situação polifônica.

À guisa de exemplificação, será analisada a peça teatral La Persistencia, uma comovente tragédia contemporânea, da dramaturga e escritora argentina Giselda Gambaro. Embora sua dramaturgia se baseie no episódio da Chechênia, em que muitas pessoas, dentre elas crianças, foram mortas de forma bárbara, o drama mantém a intertextualidade com a tragédia grega, na medida em que essa encena a agonia do herói face à força divina. Tal potência divina, no entanto, mostra-se, muitas vezes, negligente com o herói, relegando-o à própria sorte - o que faz com que tome, freqüentemente, uma via errada e sem sentido.

A via pela qual caminha o herói é o signo que constituirá o enredo trágico. A rota, que no drama antigo pode ser uma perspectiva para a vida do herói, apresenta-se, em La Persistencia, como o caminho que leva à perdição, face à violência que arrebata homens e mulheres. Quando o público entra no teatro, o cenário, majestoso e sombrio, já está à exposição. O jogo de claro e escuro que se propaga a partir das luzes acesas da platéia e da semi-escuridão do palco dá o tom prévio do horror a que se assistirá durante 
as quase duas horas de duração do espetáculo. Um palco extenso, com aproximadamente trinta metros de largura, abriga uma espécie de montanha que começa baixa na sua extremidade esquerda e quase alcança o céu na outra extremidade, podendo-se observar um ser silencioso que, passivo e impotentemente, assiste a tudo sem interferir, sempre taciturno e ereto em sua vestimenta e em seu aspecto.

Essa personagem, que se chama Silencioso, coloca-se numa relação de semelhança entre duas metades fundamentais no espaço teatral: o público e a representação. A impotência do Silencioso diante do horror da cena é a mesma da platéia diante da ação e da verdade que a ação possa, porventura, expressar. É uma relação de espelho no sentido em que Eco a exprime, como "um fenômeno-limiar, que demarca as fronteiras entre o imaginário e o simbólico" (1989:12). Na cena, o Silencioso, símbolo do criador-impotente, está calado, porque na falta de compreensão do que "deu errado", convém o silêncio. A platéia, também silenciosa, vê-se refletida no espelho-Silencioso. Imagem e realidade se confundem. $\mathrm{O}$ público busca na realidade a identificação do seu silêncio - fazendo com que ele entre no jogo proposto pela encenação e, dentro desta, pelo Silencioso - pois o público será despertado não para a realidade da representação, mas para a realidade "que se desenvolve e existe fora do campo de visão do espectador" (Pavis, 1999:171). Essa exterioridade pode estar simplesmente fora da cena como, mais amplamente, estar fora do teatro ou, ainda, fora do próprio gênero dramático. Isso, no entanto, é apenas um primeiro momento do ritual, pois num segundo momento, ele percebe tratar-se de uma imagem - não necessariamente em conexão com a realidade - e, num terceiro momento, compreende que a imagem é a sua. No espanto e na consciência da imagem refletida, como a de Narciso, consiste a dimensão trágica do espetáculo, uma vez que ele (o espectador) se vê encerrado num conflito cerrado e sem saída. Nesse estado, "manifesta-se uma matriz simbólica na qual o "eu se precipita de forma primordial e a linguagem é o que deve restituir-lhe a função particular de sujeito no universal" (Eco, 1989:12).

Em La Persistencia, a manifestação do caos primordial se encarna, externo e internamente. O cenário guarda uma imagem de abismo hiante - sempre boquiaberto e faminto - prestes a tragar a primitividade representada, também, nas vestes e no andar das personagens; salvo o Silencioso, que se mantém sempre mais ereto e de postura firme, todos os outros três personagens conservam traços de uma época primitiva. $\mathrm{O}$ casebre tosco e grotesco - o que lembra mais uma caverna - é um símbolo da carência e da primitividade.

Tudo parece ou necessita de um vir a ser. Entretanto, a perspectiva do espetáculo é mais terrível, por se tratar, ali, de um estado de coisas que deixara de ser. Utensílios domésticos muitos simples são toda a riqueza do lugar. Mesmo as vidas humanas parecem se confundir com a pobreza do espaço, como se estivessem acostumadas à dureza e à brutalidade, pois agem como se fossem animais selvagens. Nesse lugar que parece estar situado nos confins da terra ou, mitologicamente, nas profundezas do Tártaro - vivem Zaida, sempre acocorada e com o rosto coberto, e Boris, cujo único tesouro é uma pequena caixa que guarda com todo cuidado. Os dois são irmãos e vivem suas vidas imobilizadas pela guerra, que é um tempo desesperador. As relações se confundem. Até mesmo os irmãos vivem uma relação de estranheza entre si. Como não sabem amar, os sentimentos de amizade e de respeito são, todo o tempo, rompidos - o que provoca a transgressão nas regras de convivência. 
Mas no meio desse ambiente estéril, há espaço para pequenos gestos, esperanças que se vislumbram. Dentro da caixa que Boris tem na mão há alguma coisa como pequenas pedras encontradas na praia - símbolo de memórias, de caminhadas feitas em tempos de paz. Na peça, essa pequena caixa é o único símbolo de uma humanidade conservada. Ela pertencia ao filho de Zaida que, mesmo criança, foi vítima da insensatez da guerra. $O$ corpo da criança morta tinha um braço amputado. $O$ braço perdido da criança, bem como a caixa com as pedras, são ícones do que acima se apontou como a via que leva o herói rumo à sua perdição. Na peça, o horror da guerra corta de forma tão penetrante como a suave folha de papel corta, previamente, a tênue carne. A guerra, como os olhos da Górgona, petrifica, imobiliza e destitui de razão quem se deixa absorver por ela. A guerra inverte a ordem natural das coisas - a perda do filho é o símbolo da transgressão, causado pela destruição bélica. Numa relação simétrica com a figura taciturna do Silencioso, a transgressão da guerra se presentifica na relação Pai-Filho. A mãe que enterra o filho sem nada poder fazer, sem nem mesmo poder lamentá-lo, sem nem mesmo ter podido encontrar o conjunto do seu corpo é a expressão da impotência do pai face às dores dos filhos.

Na peça, essa relação está encarnada na dor silenciosa do deus-Silencioso e em seu olhar de cima para baixo. Esse deus-silencioso não tem o atrevimento de Prometeu que, burlando a atenção de Zeus, dotou o homem da capacidade de manipular os meios que lhe permitiam participar da cultura. O deus-silencioso, ao contrário, incapaz de intervir, esconde-se - sua potência parece consistir na sua imparcialidade fantasmagórica. É o espectro do vazio, não tem nome próprio, e consegue, portanto, ser neutro. Não atende a um apelo, porque ele mesmo parece não compreender o vocativo que as outras personagens ruminam. Por seu lado, Zaida e Boris já não conseguem denominar o que poderia ser um lenitivo para suas feridas. Não há um "meu Deus" que possa ser evocado, pois esse, escondido, ficou esquecido como o Prometeu de Kafka, que a águia visitou um dia, depois somente uma semana após, daí um mês, até que não tendo mais importância ficou abandonado no rochedo, sem nem mesmo ser sacrificado pela visita da águia.

Não há, por conseguinte, mobilidade. O tempo parece parado. Não há ventos que soprem para o Norte ou para o Sul. A metáfora da via não traslada, as palavras não soam suficientes para exprimir o desespero, o horror e a nulidade da situação. Tudo parece morto: a mãe, o pai, o irmão, o filho. Nesse mar de mortos, até Deus está morto. A figura espectral, cuja presença "é um emblema da transcendência, aquilo que no exercício de toda violência tem o nome do que justifica todo ato aberrante: o nome de um deus, o nome de um Deus" (Monteleone, 2007:6). A mulher, Zaida, como que tentando uma reconciliação ou buscando uma via que a leve a um lugar mais ameno, oferece ao deus-espectral-Silencioso a água - símbolo da vida mortal - mas que nesse contexto pode inferir a cessação da sede vingativa que agora une homem e Deus. Outro símbolo divino a que ela se refere é o néctar, comida divina e imortal.

Assim, a singularidade da enunciação teatral está ligada ao fato de ela frustrar uma concepção tranqüilizadora da citação. O discurso teatral constitui um setor do discurso literário caracterizado por uma dupla cena enunciativa. Portanto, como assevera Ducrot: 
[...] a língua constitui um gênero teatral particular que oferece para o sujeito falante um certo número de empregos institucionais estereotipados; a língua comporta, a título irredutível, todo um catálogo de relações inter-humanas, toda uma panóplia de papéis que o locutor pode ele próprio escolher ou impor ao destinatário” (Ducrot, 1973:128).

A partir dessa breve análise, pode-se concluir reafirmando que o objeto da Semiótica, o sentido, em seu domínio infinitamente vasto, é apreendido por meio de alegorias, cabendo ao público apreender o sentido desse discurso e reorganizar as diversas situações de enunciação.

\section{Notas}

1 “[...] uma narrativa de caráter simbólico ou alusivo. Enquanto narração é um encadeamento de atos; coloca em cena personagens (seres humanos, animais, abstrações personificadas) cujos atributos e figurinos, cujos fatos e gestos têm valor de signos, e que se movem em um lugar e em um tempo que são eles mesmos símbolos". [tradução livre]

2 “[...] um que é o aspecto imediato e literal do texto; o outro, que é sua significação moral, psicológica ou teológica”. [tradução livre]

\section{REFERÊNCIAS BIBLIOGRÁFICAS}

BERTRAND, Denis. Caminhos da semiótica literária. São Paulo: EDUSC, 2003.

DUCROT, O. La preuve et le dire. Paris: Mame, 1973.

ECO, Umberto. Sobre Espelhos e outros ensaios. Rio de Janeiro: Nova Fronteira, 1989.

FERREIRA, Aurélio Buarque de Holanda. Novo Aurélio - Dicionário da Língua Portuguesa. Rio de Janeiro: Nova Fronteira, 1999.

GAMBARO, Giselda. La persistencia. Buenos Aires: Grupo Editorial, 2007.

GUINSBURG, J.; COELHO NETO, J. Teixeira \& CARDOSO, Reni Chaves (orgs). Semiologia do Teatro: São Paulo: Perspectiva, 2006.

HELBO, André. (org.) Semiologia da representação: teatro, televisão, história em quadrinhos. São Paulo: Cultrix, s/d.

LOPES, Ivã Carlos \& HERNANDES, Nilton. (orgs) Semiótica - objetos e práticas. São Paulo: Contexto, 2005.

MAINGUENEAU, Dominique. Pragmática para o discurso literário. São Paulo: Martins Fontes, 1996.

MOISÉS, Massaud. Dicionário de Termos Literários. São Paulo: Cultrix, 1995.

MONTELEONE, Jorge. La Guerra Interminable. Buenos Aires. La Revista del complexo teatral de la ciudad de Buenos Aires. ano XXIII, nº 90, julio, 2007.

MORIER, Henri. Dictionaire de Poétique et Rhétorique. Paris: PUF, 1989.

PAVIS, Patrice. Dicionário de Teatro. São Paulo: Perspectiva, 1999.

SANTAELLA, Lúcia. O que é Semiótica. São Paulo: Brasiliense, 1983. 


\section{Como citar este artigo:}

SILVA, Edson Santos; ARAÚJO, Orlando Luiz de \& RIGOLON, Wilma. A semiótica no/do teatro em La persistencia, de Giselda Gambaro. Estudos Semióticos. [online] Disponível na Internet via WWW.URL: http://www.fflch.usp.br/dl/semiotica/es. Editor Peter Dietrich. Número 4, São Paulo, 2008.

Acesso em "dia/mês/ano". 